\title{
Who Creates Emotional Exhaustion To Salesperson? Is It, Supervisor, or Customer?
}

\author{
Rakhy KS ${ }^{1}$, Sony Vijayan ${ }^{2}$ \\ \{rakhyks@ gmail.com ${ }^{1}$, sonyvineeth@gmail.com ${ }^{2}$ \} \\ ${ }^{1,2}$ Amrita Vishwa Vidyapeetham, Dept. of Commerce and Management, Amrita School of Arts and \\ Sciences, Kochi, India
}

\begin{abstract}
The motive of this study is to explore the effect of abusive supervision and customer incivility on retail textile shops salespersons' emotional exhaustion in Indian retail work settings. Multiple interpersonal stressors on salespersons negatively influence the emotional well being and job performance. In frontline service, more than physical or mental efforts, emotional management has priority to maintain service quality. Service position requires internal and external social interactions, and negative social interaction may further move to emotional exhaustion. This study analyses the effect of abusive supervision and customer incivility on salespersons' emotional exhaustion in the Indian context. This study established high-level abusive supervision and low-level customer incivility, and abusive supervision is the primary cause of salespersons' emotional exhaustion in the Indian retail textile sector.
\end{abstract}

Keywords:Emotional exhaustion, abusive supervision, customer incivility, salespersons, retail textile shops.

\section{Introduction}

Retail commerce considers customers as a "second manager," and they have the domination and preferences, more than the salesperson. A salesperson is an employee whose job is to build a cordial relationship with customers for achieving organizational goals [1]. They have to act like a boundary spanners in between supervisors' and customers'. To bring customer loyalty and service quality, the salespersons' should facet positive and friendly emotions. In a "dog eats dog "environment, the salesperson has lots of pressure from supervisor for better service quality [2]. The prominence of the current study is on the emotional exhaustion of salespersons at the workplace, especially the interaction with supervisors and customers. This study investigates that, is there any relationship between abusive supervision, customer incivility, with emotional exhaustion of salespersons'.

\subsection{Significance of the study}

This study helps the retail sector to understand the effect of internal and external stressors like abusive supervision and customer incivilityon salespersons' emotional exhaustion. The result of this study helps retailers to rectify the source of salespersons emotional exhaustion and contributes to occupational health and safety and workplace incivility literature. The findings of the study give insight into the antecedents of salespersons' emotional exhaustion in the Indian context. 


\subsection{Statement of the problem}

Working as a salesperson is one of the stressful jobs. Usually, they are underpaid, long working hours, unorganized and untrained cutthroat competition among retailers provide maximum service facilities and improve the ambiance of the shop to attract maximum customers. Customer ill-treatment and abusive supervision are common problems among retail salespersons [3]. Emotional exhaustion may lead to the turnover intention of skilled salespersons, which may affect companies' growth. The reason for choosing a retail textile shop for the study was that as per the labor statistics from the concerned labor department, the number of employees is more in retail textile shops compare to other retail segments. Salespersons' quality of work-life is pathetic; most of the shops are locally owned without considering any employee welfares, and salespersons from retail textile shops are potential for multiple social interaction stressors [4].

\subsection{Research questions}

Reviewing the past research shows the empirical evidence of the positive relationship between abusive supervision and customer incivility towards salespersons' emotional exhaustion.therefore this study has been analyzing the role of supervisor' and customer to influence the salesperson's emotional exhaustion and addresses specific research questions like in what way salesperson get emotionally exhausted either from the supervisor or from the customer? Who gives more emotional exhaustion to a salesperson? Is it a supervisor or a customer?

\subsection{Objectives}

1.To analyze the effect of abusive supervision on emotional exhaustion of salespersons 2.To analyze the effect of customer incivility on emotional exhaustion of salespersons

\section{Literature Review and Hypothesis Development}

\subsection{Abusive supervision and emotional exhaustion}

Pines and Aronson(1988) define "emotional exhaustion involves primarily feeling of helplessness, hopelessness, and entrapment."Emotional exhaustion is one of the significant consequences of abusive supervision at work. Emotional exhaustion is one negative and dysfunctional attitude in the work environment. According to Tepper, "abusive supervision as a subordinate perception of the extent to which supervisor engaged in sustained hostile verbal and non- verbal behaviors, excluding physical contact."(Tepper, 2000). Abusive supervision causes emotional exhaustion, and workplace deviance behavior among employees' and it will affect their customer- service[5]

H1. Abusive supervision has a positive relationship with emotional exhaustion. 


\subsection{Customer incivility and emotional exhaustion}

Customer incivility is an external stressor "who displays uncivic behaviors such as being rude or speaking in a discourteous or abusive manner." [6]. In the service sector, both customer and employee have an equal role in improving the service process, so customer-related emotional exhaustion among salesperson is pervasive. The salesperson has to maintain good emotions to rude as well as kind customers. Pleasing interaction with customers is one of the leading indicators of salesperson service quality[7]. Customer ill-treatment is a common problem in the service sector, and it can result in employee emotional exhaustion and poor mental health[8]. Emotional demands at work and customer incivility are positively related to the emotional exhaustion of a salesperson[9]. Some other research shows that interacting with a customer is not always create emotional strain [10]. Emotional labor may alienate the worker from work, but customer service can regulate this alienation into alleviation [11]

H2. Customer incivility has a negative relationship with emotional exhaustion

\section{Methodology and Data Analysis}

\subsection{Research design}

This research design is descriptive and single cross-sectional. It describes the relationships among the concepts.

\subsection{Sample}

The population of this study is salespersons' who are working in retail textile shops. For collecting primary data, a simple random sampling technique is used. In the first stage the research is limited to her study to the state of Kerala(one of the southern state of India), As per the labor statistics from the concerned labor department, three districts are selected based on the highest number of salespersons'. Among these three districts, 398 samples are collected randomly.

\subsection{Measures}

To assess emotional exhaustion, seven items scale were used developed by Pines \&Aronson (1988). Abusive supervision was assessed by using three items by Tepper, B.J.(2000), and customer incivility assessed with a three-item scale developed by Wilson \& Holmall (2013).

\section{Results and Discussions}

\subsection{Multiple regression analysis}

Multiple regression method has used to measure the effect of abusive supervision and customer incivility on salespersons' emotional exhaustion. Multiple regression can able to 
analyze how a set of independent variables predict one dependent variable, and which is the best predictor of an outcome. IBM spss statistics 25 was used for the data analysis.

\subsection{Descriptive statistics}

Mean, standard deviation, multiple correlations, and reliability among all variables listed below in table 1

Table 1. Salespersons: Corelations,Means,Std.Ds, and Reliability.

\begin{tabular}{llll}
\hline Heading level & Customer Incivility & $\begin{array}{l}\text { Abusive } \\
\text { Supervision }\end{array}$ & $\begin{array}{l}\text { Emotional } \\
\text { Exhaustion }\end{array}$ \\
\hline $\begin{array}{l}\text { Customer } \\
\text { Incivility }\end{array}$ & & & \\
$\begin{array}{l}\text { Abusive } \\
\text { Supervision }\end{array}$ & .274 & & \\
$\begin{array}{l}\text { Emotional } \\
\text { Exhaustion }\end{array}$ & -.217 & -.845 & \\
$\begin{array}{l}\text { Mean } \\
\text { Standard }\end{array}$ & 12.81 & & \\
$\begin{array}{l}\text { Deviation } \\
\text { Reliability }\end{array}$ & 1.404 & 9.77 & 14.06 \\
& .866 & 3.775 & 9.724 \\
\hline
\end{tabular}

\subsection{Hypothesis testing}

Multiple regression analysis has used to test the research hypothesis. Table. 2 shows the effectiveness and quality of the predictor variable on the dependent variable depend on the result of 'R,' which represents the value of the multiple correlation coefficient. In the below table 2 model summary, the ' $\mathrm{R}$ ' value is .943 , indicates the right level of prediction. R square value or the coefficient of determination shows that independent variables explain $88.9 \%$ validity on the dependent variable.

Table 2. Multiple regression results: emotional exhaustion of salespersons from abusive supervision and customer incivility.

\begin{tabular}{llllllll}
\hline Variables & $\mathbf{R}$ & $\mathbf{R}^{2}$ & $\mathbf{B}$ & $\mathbf{S . E}$ & $\boldsymbol{\beta}$ & $\mathbf{t}$ & Sig. \\
\hline & .943 & .889 & & & & & \\
$\begin{array}{l}\text { Abusive } \\
\text { Supervision }\end{array}$ & & 2.126 & .038 & .951 & 55.335 & .000 \\
$\begin{array}{l}\text { Customer } \\
\text { Incivility }\end{array}$ & & -2.40 & .092 & -.045 & -2.597 & .010 \\
\hline
\end{tabular}


In table 2, The unstandardized coefficient Beta value (B) shows how much the dependent variable varies with the influence of the one predictor variable when all other predictor variables are constant.' B' value shows that abusive supervision has a positive effect on emotional exhaustion (2.126), and emotional exhaustion due to customer incivility shows a negative relationship $(-.2 .40)$. The standardized coefficient beta columns (.951 and -.045) are equal to zero and $\mathrm{P}<.05$, then the coefficient is statistically significant.

Multiple regressions were tested to predict the emotional exhaustion of salespersons from abusive supervision and customer incivility. Among these independent variables, abusive supervision is positively related to emotional exhaustion $\mathrm{F}(2,395)=1578.085, \mathrm{P}<.05$ and ' $\mathrm{R}$ ' square $=.889$. So the first hypothesis(H1) was accepted. Customer incivility has not much but a negative correlation on salespersons' emotional exhaustion, so the second hypothesis is also accepted (H2). All variables are statistically significant. The result of the study depicted that the intensity and frequency of customer incivility are less in retail textile shops, and it is not affecting emotional stability. Customer incivility may influence salespersons depends on its intensity and frequency[11].

\section{Conclusion}

Scholarly studies related to emotional exhaustion in the retail sector are scarce in India. The present study is trying to explore the work-related emotional exhaustion and other multiple stressors of employees. In India, we can see two categories of shops one is well organized and professional, and they have a systematic management style, human resource, and customer management system. Another category is locally managed shops. They do not have any distinct organizational culture, especially in semi-urban and rural areas. Most of them are underpaid and long working hours, no resting time. Supervisors are also not professionally trained. Most of them are rude and not concern about employees' quality of work-life. Avoiding abusive supervision is an essential aspect of the growth of the retail sector; otherwise, employee turnover will increase again and again, and retailers may lose skilled employees from their store.

\section{Limitations}

The study analyzed the data derived from 3 districts out of 14 districts, and this study considered and collected data from retail textile shops only, and results may differ if applied in different retail sectors. This study has not analyzed the outcome of emotional exhaustion. This study has based on a short-term survey. The data were collected from India, having different business settings and organizational structure; the results may not apply to other cultural contexts.

\section{Suggestions}

Our findings suggest that retail textile shops can control their internal social stressors through several techniques such as zero-tolerance policy, training programs, and improved leadership practices for supervisors [12]. Provide a platform for salespersons to complain about 
supervisors or customers and find out an immediate solution for their complaints. Always keep the quality of the product, whether it is tangible or intangible may reduce incivility from customers. Select a representative from salespersons' to address their work-related issues. Supervisors themselves focus on positive behavior for the benefit of the retail outlets. Those organizations that try to maintain good long-term relationships and loyalty from salespersons must have to improve their psychosocial work environment.

\section{References}

[1] T. L. Chung, B. Rutherford, and J. Park, "Understanding multifaceted job satisfaction of retail employees," Int. J. Retail Distrib. Manag., vol. 40, no. 9, pp. 699-716, 2012, doi: 10.1108/09590551211255974.

[2] R. S. Singh, "India's Service Sector - Shaping Future of Indian Retail Industry," Procedia Econ. Financ., vol. 11, no. 14, pp. 314-322, 2014, doi: 10.1016/s22125671(14)00199-3.

[3] N. Sharma and V. K. Singh, "Effect of workplace incivility on job satisfaction and turnover intentions in India," South Asian J. Glob. Bus. Res., vol. 5, no. 2, pp. 234-249, 2016, doi: 10.1108/sajgbr-02-2015-0020.

[4] V. G. Raaj and E. N. Anju, "Unseen incivility in workplace and its impact on work allied outcomes," Int. J. Eng. Adv. Technol., vol. 8, no. 3, pp. 80-85, 2019.

[5] Z. Akram, Y. Li, and U. Akram, "When employees are emotionally exhausted due to abusive supervision. A conservation-of-resources perspective," Int. J. Environ. Res. Public Health, vol. 16, no. 18, 2019, doi: 10.3390/ijerph16183300.

[6] D. D. Walker, D. D. van Jaarsveld, and D. P. Skarlicki, "Exploring the effects of individual customer incivility encounters on employee incivility: The moderating roles of entity (in)civility and negative affectivity," J. Appl. Psychol., vol. 99, no. 1, pp. 151-161, 2014, doi: 10.1037/a0034350.

[7] T. T. Kim, S. Paek, C. H. Choi, and G. Lee, "Frontline service employees' customerrelated social stressors, emotional exhaustion, and service recovery performance: Customer orientation as a moderator," Serv. Bus., vol. 6, no. 4, pp. 503-526, 2012, doi: 10.1007/s11628-012-0164-8.

[8] B. Menguc, S. Auh, V. Yeniaras, and C. S. Katsikeas, "The role of climate: implications for service employee engagement and customer service performance," $J$. Acad. Mark. Sci., vol. 45, no. 3, pp. 428-451, 2017, doi: 10.1007/s11747-017-0526-9.

[9] D. D. van Jaarsveld, D. D. Walker, and D. P. Skarlicki, "The role of job demands and emotional exhaustion in the relationship between customer and employee incivility," $J$. Manage., vol. 36, no. 6, pp. 1486-1504, 2010, doi: 10.1177/0149206310368998.

[10] C. Williams, "Sky service: The demands of emotional labour in the airline industry," Gender, Work Organ., vol. 10, no. 5, pp. 513-550, 2003, doi: 10.1111/1468-0432.00210.

[11] M. B. Tolich, "Alienating and liberating emotions at work: Supermarket Clerks' Performance of Customer Service," J. Contemp. Ethnogr., vol. 22, no. 3, pp. 361-381, 1993, doi: 10.1177/089124193022003004.

[12] C. M. Pearson and C. L. Porath, "On the nature, consequences and remedies of workplace incivility: No time for 'nice'? Think again," Acad. Manag. Exec., vol. 19, no. 1, pp. 7-18, 2005, doi: 10.5465/ame.2005.15841946. 